\title{
Pd-catalyzed ethylene methoxycarbonylation with Brønsted acid ionic liquids as promoter and phase-separable reaction media
}

Garcia-Suarez, Eduardo J.; Khokarale, Santosh Govind; Nguyen van Buu, Olivier; Fehrmann, Rasmus; Riisager, Anders

Published in:

Green Chemistry

Link to article, DOI:

$10.1039 / \mathrm{c} 3 g c 41380 \mathrm{~b}$

Publication date:

2014

Document Version

Publisher's PDF, also known as Version of record

Link back to DTU Orbit

Citation (APA):

Garcia-Suarez, E. J., Khokarale, S. G., Nguyen van Buu, O., Fehrmann, R., \& Riisager, A. (2014). Pd-catalyzed ethylene methoxycarbonylation with Brønsted acid ionic liquids as promoter and phase-separable reaction media. Green Chemistry, 16, 161-166. https://doi.org/10.1039/c3gc41380b

\section{General rights}

Copyright and moral rights for the publications made accessible in the public portal are retained by the authors and/or other copyright owners and it is a condition of accessing publications that users recognise and abide by the legal requirements associated with these rights.

- Users may download and print one copy of any publication from the public portal for the purpose of private study or research.

- You may not further distribute the material or use it for any profit-making activity or commercial gain

- You may freely distribute the URL identifying the publication in the public portal 


\title{
Green Chemistry
}

PAPER

Cite this: Green Chem., 2014, 16, 161

\section{Pd-catalyzed ethylene methoxycarbonylation with Brønsted acid ionic liquids as promoter and phase-separable reaction media $\dagger$}

\author{
Eduardo J. García-Suárez, Santosh G. Khokarale, Olivier N. van Buu, \\ Rasmus Fehrmann and Anders Riisager*
}

Brønsted acid ionic liquids (BAILs) were prepared and applied as combined acid promoters and reaction media in $\mathrm{Pd}$-phosphine catalyzed methoxycarbonylation of ethylene to produce methyl propionate. The BAILs served as alternatives to common mineral acids required for the reaction, e.g. methanesulfonic acid or sulfuric acid, resulting in high catalytic activity and selectivity towards methyl propionate. In addition, the BAILs yielded a biphasic system with the product and provided stability to palladium intermediates avoiding the undesirable formation of palladium black after reaction. These special features enabled facile methyl propionate separation and recovery of the ionic liquid catalyst system, thus allowing its re-use up to 15 times without apparent loss of catalytic activity or selectivity.

Received 11th July 2013,

Accepted 12th September 2013

DOI: $10.1039 / c 3 g c 41380 b$

www.rsc.org/greenchem $p$-toluenesulfonic acid (TSA) or sulfuric acid (SA)) is needed to promote the reaction. ${ }^{6}$ The main roles of the acid are to preserve catalytic activity by facilitating protonation of catalytically inactive $\operatorname{Pd}(0)$ species into active $[\mathrm{Pd}(\mathrm{II})-\mathrm{H}]^{+}$species, and to stabilize intermediate cationic $\mathrm{Pd}(\mathrm{II})$ species formed during the catalytic cycle by weak coordination to the anions from the acid. $^{6 a, 7}$ Major drawbacks of applying such acids are their manipulation, corrosion of reaction equipment and fast phosphine alkylation when using monodentate phosphines. Consequently, some attempts to avoid these drawbacks have been made by the employment of alternative acid promoters such as, e.g., polymeric sulfonic acids, borate esters, and aluminium triflate, instead of using common mineral acids. ${ }^{8}$

The use of ionic liquids (ILS) as reaction media in liquidliquid biphasic reactions makes in many cases the processes greener than when using traditional organic solvents, due to the IL advantages such as low vapor pressure, good thermal stability, tunable solubility and acidity/coordination properties. ${ }^{9}$ Furthermore, ILs can also relatively easily be designed to accommodate functional groups which can provide the ILs with auxiliary reactivity like, e.g., Brønsted acidity. ${ }^{10}$ In line with this, Brønsted acid ionic liquids (BAILs) have been used successfully as alternative to mineral acids in many reactions. ${ }^{11}$

In this work, we introduce a versatile reaction concept for Pd-phosphine catalyzed methoxycarbonylation of ethylene to produce MP, where BAILs function as reaction media as well as alternative acid promoters to the commonly used strong acids (Fig. 1). The application of BAILs led to excellent results in terms of both catalytic activity and selectivity. Furthermore,
Centre for Catalysis and Sustainable Chemistry, Department of Chemistry, Technical University of Denmark, DK-2800 Kgs. Lyngby, Denmark. E-mail: ar@kemi.dtu.dk; Fax: (+45) 45883136

$\dagger$ Electronic supplementary information (ESI) available. See DOI: 10.1039/ c3gc41380b 


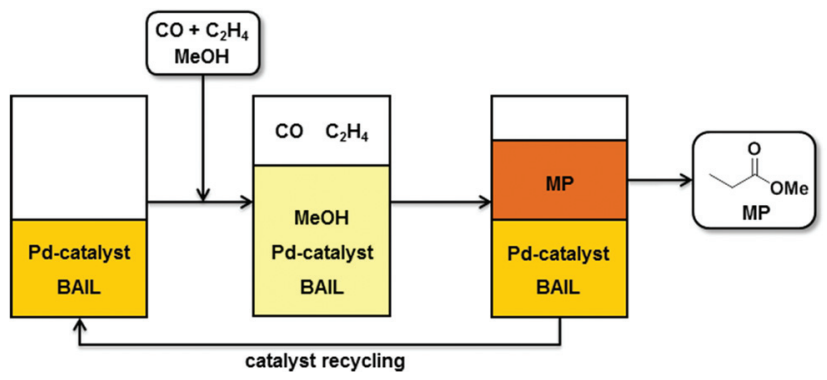

Fig. 1 Schematic representation of ethylene methoxycarbonylation with BAILs as reaction media with MP product separation and Pd-catalyst recycling.

the employed BAILs provide highly efficient immobilization of the palladium complex catalyst as well as a good stability of the catalytic Pd-intermediates. These features avoid the formation of palladium black and enable facile catalyst recovery and reutilization.

\section{Experimental}

\subsection{Materials}

Triethylamine ( $\geq 99 \%)$, pyridine ( $\geq 99.8 \%)$, 1-methylimidazole ( $\geq 99 \%)$, methanesulfonic acid (MSA, $\geq 98 \%$ ), $p$-toluenesulfonic acid (TSA, $\geq 98.5 \%$ ), sulfuric acid (SA, 95-97\%), triphenylphosphine $(\geq 95 \%)$, 1,4-butanesultone (99.97\%), methanol $(\geq 99.8 \%)$, palladium acetate (99.98\%), 1,2-bis(di-tert-butylphosphinomethane)benzene (DTBPMB, $\geq 98 \%$ ) and 1-butyl-3-methylimidazolium methanesulfonate ([BMIm] $\left.\left[\mathrm{MeSO}_{3}\right]\right)(\geq 95 \%)$ were purchased from Sigma-Aldrich and used without further purification. A gas mixture with a molar composition of $\mathrm{CO}: \mathrm{C}_{2} \mathrm{H}_{4}$ : $\mathrm{Ar}=2: 2: 1$ was purchased from AGA and used as received for the methoxycarbonylation reactions.

\subsection{Synthesis and characterization of Brønsted acid ionic liquids (BAILs)}

The employed BAILs were synthesized in two reaction steps following a slightly different procedure to that previously reported in the literature. ${ }^{12}$ The first reaction step involved the synthesis of zwitterions ${ }^{13}$ which were subsequently converted to BAILs by reaction with an equimolar amount of the corresponding acid (Scheme 2, see ESI† for details).

${ }^{1} \mathrm{H}$ and ${ }^{31} \mathrm{P}\left\{{ }^{1} \mathrm{H}\right\}$ NMR spectra of the synthesized BAILs were recorded using either a Varian Mercury $300 \mathrm{MHz}$ or a Varian Unity Inova $500 \mathrm{MHz}$ spectrometer (ESI†).

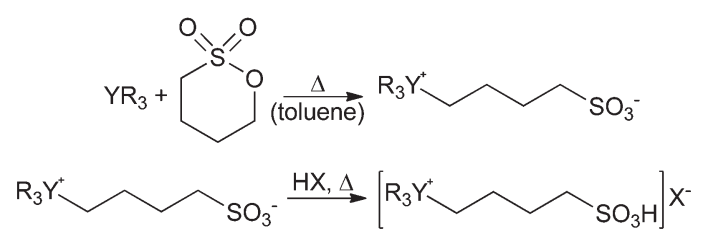

Scheme 2 Synthesis route of the BAILs. ${ }^{12,13} \mathrm{YR}_{3}=1$-methylimidazole, pyridine, triethylamine or triphenylphosphine; $\mathrm{HX}=$ methanesulfonic acid (MSA), p-toluenesulfonic acid (TSA) or sulfuric acid (SA).
The thermal stability of the BAILs was evaluated by thermal gravimetric analysis (TGA) using a Mettler Toledo (TGA/DSC1

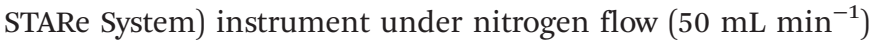
(ESI $\dagger$ ). In a typical experiment the BAIL was heated from room temperature to $120{ }^{\circ} \mathrm{C}$ with a heating rate of $10{ }^{\circ} \mathrm{C} \mathrm{min}^{-1}$. The sample was dried at this temperature for $2 \mathrm{~h}$ in order to eliminate moisture. Then, the sample was heated from $120^{\circ} \mathrm{C}$ to $600{ }^{\circ} \mathrm{C}$ with a ramp rate of $10^{\circ} \mathrm{C} \mathrm{min}^{-1}$.

The relative acidity of the BAILs (and other applied Brønsted acids) was evaluated using a Cary 5000 UV-Vis spectrophotometer with 4-nitroaniline as the indicator according to reported procedures. ${ }^{14}$ In a typical experiment an ethanolic solution of 4-nitroaniline $(0.1 \mathrm{mM})$ was added to a solution of the corresponding acid $(10 \mathrm{mM})$ and the mixture was stirred overnight. Thereafter, the absorbance was measured and compared with the absorbance of a reference 4-nitroaniline solution. The absorbance difference was correlated to the Brønsted acidity through the Hammett acidity function $H_{0}=\mathrm{p} K(I)+$ $\log \left[\mathrm{IH}^{+}\right] /[\mathrm{I}]$, where $\mathrm{p} K(I)$ is the $\mathrm{p} K_{\mathrm{a}}$ value of the indicator referred to an aqueous solution, and $[\mathrm{I}]$ and $\left[\mathrm{IH}^{+}\right]$are the molar concentrations of the un-protonated and protonated forms of the indicator, respectively.

\subsection{Methoxycarbonylation of ethylene with BAILS}

Catalytic experiments were performed in a $50 \mathrm{~mL}$ stainless steel Parr reactor equipped with a pressure transducer (Parr 4843). In a typical experiment palladium(II) acetate $(11.2 \mathrm{mg}$, $0.05 \mathrm{mmol}, \quad 0.3 \mathrm{~mol} \% \mathrm{Pd}$ ), 1,2-bis(di-tert-butylphosphinomethyl)benzene, DTВРМв (98.7 mg, $0.25 \mathrm{mmol}$, ligand/Pd molar ratio of 5) and $6 \mathrm{~mL}$ of a solution of the corresponding BAIL in $\mathrm{MeOH}$ (32 wt\%) were introduced into the reactor directly or after stirring for $2 \mathrm{~h}$ under $\mathrm{Ar}$ at $80{ }^{\circ} \mathrm{C}$ in order to pre-activate the catalytic system. Afterwards, the reactor was flushed three times with the gas mixture of $\mathrm{CO}: \mathrm{C}_{2} \mathrm{H}_{4}: \mathrm{Ar}$, pressurized to 20 bars and heated to $80^{\circ} \mathrm{C}$ where the reaction was carried out. The conversion of the reactants was followed and correlated to the pressure drop of the reaction mixture after pre-calibration of the pressure transducer. After the reaction, the reactor was cooled down, depressurized and the product was analyzed by GC-FID (Agilent, 6890N, DB-1 capillary column, $50 \mathrm{~m} \times 0.320 \mathrm{~mm}$ ) to confirm the high purity of the formed MP.

For the recycling experiments the reactor was re-pressurized with the gas mixture up to 20 bars after cooling and depressurizing, as described above. After every fifth reaction run the MP phase was removed and fresh $5 \mathrm{~mL} \mathrm{MeOH}$ was added.

\section{Results and discussion}

\subsection{Synthesis and characterization of BAILs}

Six different BAILs consisting of different cations bearing an alkylsulfonated moiety and anions were prepared following a slightly modified reported procedure (Fig. 2). ${ }^{12}$ The purity of the prepared BAILs was confirmed by NMR spectroscopy and the thermal stability was measured by TGA (see ESI $\dagger$ ). In 


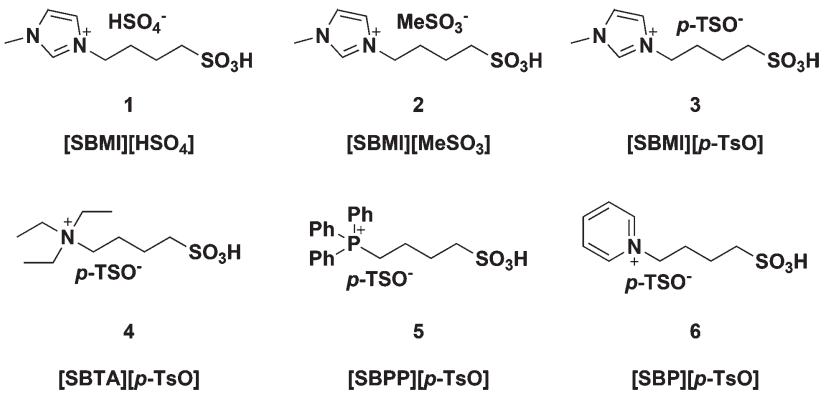

Fig. 2 Overview of the synthesized BAILs.

addition, calculation of the Hammett acidity function of the BAILs was carried out in order to validate their acidic properties.

The TGA profiles confirmed that the synthesized BAILs were thermally stable up to their decomposition temperature of $280-310{ }^{\circ} \mathrm{C}$. No direct relationship was found between the decomposition temperature and the cation and/or anion composition. However, the phosphonium based BAIL [SBPP][ $p$-TsO] (5) proved to be more thermally stable $\left(T_{\mathrm{d}}=310^{\circ} \mathrm{C}\right)$ than the nitrogen based analogues, as also reported in the literature. ${ }^{15}$

The Hammett method consists of the determination of acidity functions using UV-Vis spectroscopy, where a basic indicator is used to trap the dissociative proton. ${ }^{14}$ In this work, 4-nitroaniline was selected as an indicator and ethanol was used as a solvent since most of the prepared BAILs were soluble herein. A maximum absorbance $\left(A_{\max }\right)$ of 1.65 was observed at $\lambda_{\max }=370 \mathrm{~nm}$ in ethanol for the un-protonated form of 4-nitroaniline. This absorbance decreased gradually when the concentration of the BAILs was increased, thus allowing the Hammett acidity function $\left(H_{0}\right)$ to be calculated from the ratio of the measured absorbances of the unprotonated ([I] ) and protonated forms ([IH $\left.\left.{ }^{+}\right]\right)$of 4-nitroaniline (Table 1).

The Hammett acidity functions $\left(H_{0}\right)$ of the examined BAILs 1 and 3-5 (2 and $\mathbf{6}$ were not soluble enough in ethanol to allow the determination) were found to be quite similar, in the range of 2.06-2.12, thus suggesting only a minor influence of the anion and/or cation backbone structure on acidity. In

Table 1 Hammett acidity functions $\left(H_{0}\right)$ of BAILs and other Brønsted acids $^{a}$

\begin{tabular}{llrrll}
\hline Entry & Material & $A_{\max }{ }^{b}$ & \multicolumn{1}{c}{]$(\%)$} & {$\left[\mathrm{IH}^{+}\right](\%)$} & $H_{0}$ \\
\hline 1 & - & 1.65 & 100.0 & 0.0 & - \\
2 & $\mathrm{MeSO}_{3} \mathrm{H}$ & 1.52 & 92.2 & 7.8 & 2.06 \\
3 & $\mathrm{H}_{2} \mathrm{SO}_{4}$ & 1.51 & 91.5 & 8.5 & 2.02 \\
4 & $p$-TsOH & 1.49 & 90.9 & 9.1 & 1.99 \\
5 & {$[\mathrm{SBMI}]\left[\mathrm{HSO}_{4}\right](\mathbf{1})$} & 1.54 & 93.2 & 6.8 & 2.12 \\
6 & {$[\mathrm{SBMI}][p$-TsO] (3) } & 1.53 & 93.0 & 7.0 & 2.11 \\
7 & {$[\mathrm{SBTA}][p$-TsO] (4) } & 1.52 & 92.1 & 7.9 & 2.06 \\
8 & {$[\mathrm{SBPP}][p$-TsO] (5) } & 1.53 & 93.0 & 7.0 & 2.11 \\
9 & {$[\mathrm{BMIm}]\left[\mathrm{MeSO}_{3}\right]$} & 1.64 & 99.4 & 0.6 & 3.22
\end{tabular}

${ }^{a} H_{0}=\mathrm{pK}[\mathrm{I}]_{\mathrm{aq}}+\log \left([\mathrm{I}]_{\mathrm{s}} /\left[\mathrm{IH}^{+}\right]_{\mathrm{s}}\right)$. 4-Nitroaniline and the BAILs were dissolved in ethanol with $0.1 \mathrm{mM}$ and $10 \mathrm{mM}$, respectively. ${ }^{b}$ Average absorbance at $\lambda=370 \mathrm{~nm}$ of three measurements. contrast, the non-functionalized IL 1-butyl-3-methylimidazolium methanesulfonate ([BMIm] $\left[\mathrm{MeSO}_{3}\right]$ ) revealed an $H_{0}$ of 3.22 with an $A_{\max }$ value of 1.64 , which was very close to the absorbance measured for the indicator 4-nitroaniline alone (1.65). This showed that the non-functionalized IL possessed very poor acidity, thus confirming the acidity of the BAILs to be correlated to the $-\mathrm{SO}_{3} \mathrm{H}$ group functionalization, as also expected.

\subsection{Methoxycarbonylation of ethylene with BAILs}

The prepared BAILs 1-6 were tested as combined acid promoters and reaction media in the methoxycarbonylation of ethylene for producing MP ( $32 \mathrm{wt} \%$ in methanol). For comparison the non-functionalized $\mathrm{IL}[\mathrm{BMIm}]\left[\mathrm{MeSO}_{3}\right]$ was also tested as reaction medium to demonstrate the decisive role of acid functionalization of the ILs (i.e. $-\mathrm{SO}_{3} \mathrm{H}$ group) in their successful application in the reaction. Similarly, the mineral acid $\mathrm{MeSO}_{3} \mathrm{H}$ was used as an acid promoter in catalytic amounts instead of the BAILs to benchmark the performance of the BAILs. In all reactions $\mathrm{Pd}(\mathrm{OAc})_{2}$ was selected as the catalyst precursor in combination with the diphosphine ligand DTBPMB, which has been reported to result in highly selective and active methoxycarbonylation systems for MP production. ${ }^{5 a}$ The obtained results are compiled in Table 2.

Firstly, methoxycarbonylation of ethylene was performed using $\mathrm{MeSO}_{3} \mathrm{H}$ (5 equivalents) as an acid promoter in the presence of 1.2 or 5 equivalents of DTBPMB ligand (Table 2, entries 1 and 2). In both cases very high catalytic activity was obtained and a conversion of about $99 \%$ was achieved after 10 min of reaction with no apparent difference in reactivity pattern. However, a significant difference in the visual appearance of the post-reaction mixtures was indeed observed, as depicted in Fig. 3. When only 1.2 equivalents of the ligand were used a large amount of Pd-black was obviously formed, thus confirming the ligand amount to be insufficient to stabilize catalytically active palladium species. On the other hand, formation of Pd-black seemed to be avoided when 5

Table 2 Methoxycarbonylation of ethylene in the presence of BAILs, $\mathrm{MeSO}_{3} \mathrm{H}$ or non-functionalized IL ${ }^{\mathrm{a}}$

\begin{tabular}{lllll}
\hline Entry & Acid promoter & $H_{0}$ & $\begin{array}{l}\text { Conversion } \\
(\%)\end{array}$ & $\begin{array}{l}\text { MP selectivity } \\
(\%)\end{array}$ \\
\hline $1^{b, c}$ & $\mathrm{MeSO}_{3} \mathrm{H}$ & 2.06 & 99.2 & $>99$ \\
$2^{b}$ & $\mathrm{MeSO}_{3} \mathrm{H}$ & 2.06 & 98.7 & $>99$ \\
3 & {$\left[\mathrm{SBMI}_{[}\left[\mathrm{HSO}_{4}\right](\mathbf{1})\right.$} & 2.12 & 95.3 & $>99$ \\
4 & {$[\mathrm{SBMI}]\left[\mathrm{MeSO}_{3}\right](2)$} & - & 99.2 & $>99$ \\
5 & {$[\mathrm{SBMI}][p$-TsO] (3) } & 2.11 & 99.1 & $>99$ \\
6 & {$[\mathrm{SBTA}][p-\mathrm{TsO}](\mathbf{4})$} & 2.06 & 99.2 & $>99$ \\
7 & {$[\mathrm{SBPP}][p-\mathrm{TsO}](\mathbf{5})$} & 2.11 & 98.3 & $>99$ \\
8 & {$[\mathrm{SBP}][p-\mathrm{TsO}](6)$} & - & 98.7 & $>99$ \\
$9^{d}$ & {$[\mathrm{BMIm}]\left[\mathrm{MeSO}_{3}\right]$} & 3.22 & $<1$ & $>99$
\end{tabular}

${ }^{a}$ Reaction conditions: $0.05 \mathrm{mmol} \mathrm{Pd}(\mathrm{OAc})_{2}$ (0.3 mol\% Pd), DTBPMB : Pd mol ratio $=5: 1,6 \mathrm{~mL}$ of a $32 \mathrm{wt} \%$ solution of BAIL or IL in methanol, $\mathrm{P}\left(\mathrm{CO}: \mathrm{C}_{2} \mathrm{H}_{4}: \mathrm{Ar}=2: 2: 1\right)=22$ bars, $T=80^{\circ} \mathrm{C}, t=20$ min. ${ }^{b}$ With 5 equivalents of $\mathrm{MeSO}_{3} \mathrm{H}$ (acid: $\mathrm{Pd}$ mol ratio $=5: 1$ ) instead of the BAIL, $t=10$ min. ${ }^{c}$ With 1.2 equivalents of DTBPMB. ${ }^{d} t=120 \mathrm{~min}$. 

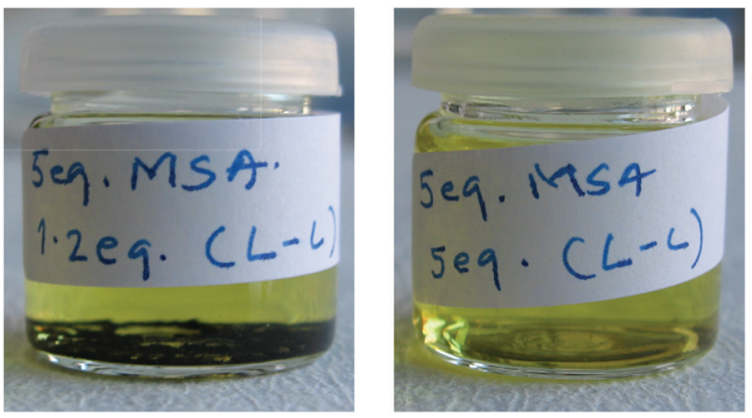

Fig. 3 Reaction mixtures after Pd-DTBPMB catalyzed ethylene methoxycarbonylation with $\mathrm{MeSO}_{3} \mathrm{H}$ as an acid promoter and DTBPMB : $\mathrm{Pd}$ ratio $=1.2: 1$ (left) and DTBPMB : Pd ratio $=5: 1$ (right).

equivalents of the ligand were used and a clear yellow solution was obtained. Based on these findings, reaction conditions with 5 equivalents of the diphosphine ligand were selected for further experiments with the BAILs.

In the reactions where the BAILs were used as acid promoters in place of $\mathrm{MeSO}_{3} \mathrm{H}$ the reaction rates were somewhat lower, but excellent conversions of about 99\% were still achieved in only $20 \mathrm{~min}$ (Table 2, entries 3-8) and - very importantly - the selectivity to MP remained higher than $99 \%$ (i.e. $\geq 98 \%$ MP yields). The observed activity difference cannot be correlated to the Brønsted acidity of the BAILs and $\mathrm{MeSO}_{3} \mathrm{H}$, which were almost identical. Instead, the lower reaction rates were likely an effect of the lower solubility of the reactant gases in the BAIL-MeOH systems compared to pure $\mathrm{MeOH}$, as normally observed in biphasic IL reaction systems, ${ }^{9}$ or the interference of the BAILs with the catalyst system. However, no influence on the catalytic activity of the cation structure and/or anion of the employed BAILs could directly be confirmed under the studied reaction conditions.

The non-functionalized IL $[\mathrm{BMIm}]\left[\mathrm{MeSO}_{3}\right]$ was also tested as reaction medium (in the absence of acid promoter) under comparable reaction conditions. As expected, almost no conversion was achieved after 120 min of reaction (Table 2, entry 9). This demonstrates clearly that functionalization of the ILs with a strong acidic moiety, such as a sulfonic acid group, has

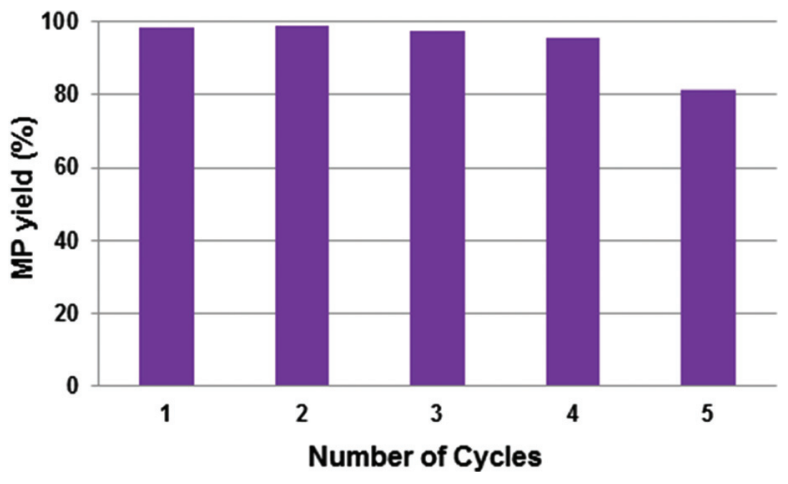

Fig. 4 Recycling experiments using the BAIL [SBMI][ $p$-TsO] (3) as reaction media and an acid promoter in the methoxycarbonylation of ethylene (reaction conditions: $0.05 \mathrm{mmol} \mathrm{Pd}(\mathrm{OAc})_{2} \quad(0.3 \mathrm{~mol} \% \mathrm{Pd})$, DTBPMB : Pd mol ratio $=5: 1,6 \mathrm{~mL}$ of a $32 \mathrm{wt} \%$ solution of BAIL in methanol, $\mathrm{P}\left(\mathrm{CO}: \mathrm{C}_{2} \mathrm{H}_{4}: \mathrm{Ar}=2: 2: 1\right)=22$ bars, $\left.T=80^{\circ} \mathrm{C}, t=20 \mathrm{~min}\right)$.

a pivotal influence on the catalytic performance of the system under the selected reaction conditions.

One of the most important issues - and a common challenge in homogeneous catalysis - is the recovery and re-use of the catalytic system. ${ }^{16}$ In the reaction concept introduced in this study the role of the applied BAILs was not only to act as an acid promoter, but also to provide facile separation of the MP product by phase-separation and to preserve the catalyst solvation (see Fig. 1).

With this consideration in mind, the recyclability of the catalytic system with [SBMI][ $p$-TSO] (3) was tested as a representative example of all the BAIL systems. The recycling experiments were carried out under the same reaction conditions used in the previous reactions, and the results are shown in Fig. 4.

As shown in Fig. 4, the catalytic system could be re-used four times with intermediate pressurizing of the reactor without any apparent loss of activity. However, after the fifth reaction run the activity was somewhat lowered due to Pd-black formation (Fig. 5a). We believe that the interaction of $\mathrm{Pd}(\mathrm{OAc})_{2}$ with the reactants - especially with $\mathrm{CO}$ which is a known reducing agent for homogeneous catalysts leading to
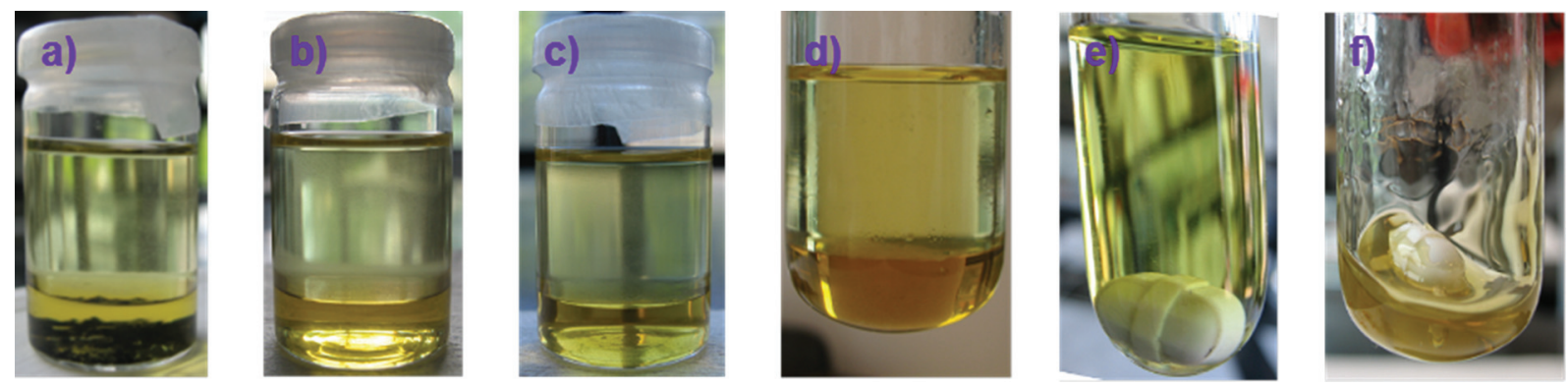

Fig. 5 (a) Biphasic reaction mixture after five reaction runs using the in situ generated catalyst system (a large amount of Pd-black). (b) Biphasic reaction mixture after five reaction runs using the preformed catalyst system (no Pd-black). (c) Biphasic reaction mixture after ten reaction runs using the preformed catalyst system (no Pd-black). (d) Biphasic reaction mixture after fifteen reaction runs using the preformed catalyst system (no Pd-black). (e) Solution of the pre-formed catalytic system containing Pd(OAc) ${ }_{2}$, DTBPMB, MeOH and the BAIL (3). (f) The BAIL phase containing the dissolved palladium catalyst after MP evaporation after the fifteenth reaction run (no Pd-black). 


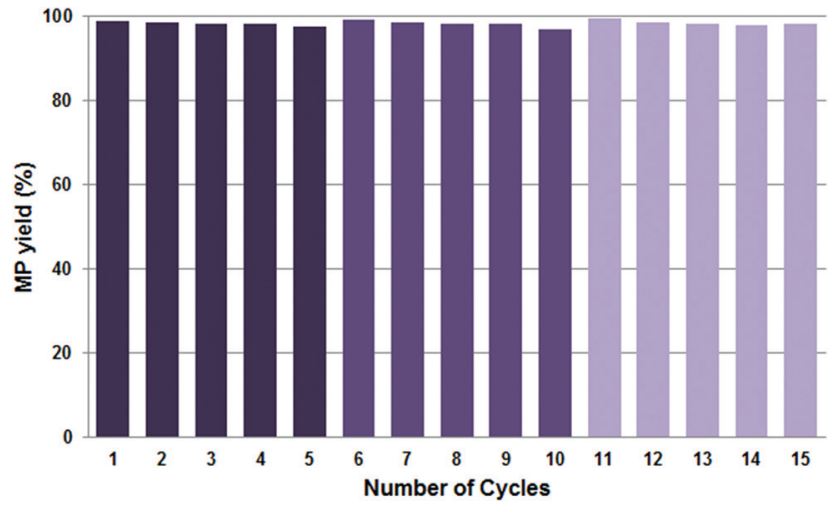

Fig. 6 Recycling experiments using BAIL (3) (after pre-formation) as reaction media and acid promoter in the methoxycarbonylation of ethylene with selectivity to MP > 99\% (reaction conditions: $0.05 \mathrm{mmol}$ $\mathrm{Pd}(\mathrm{OAc})_{2}(0.3 \mathrm{~mol} \% \mathrm{Pd}), \mathrm{DTBPMB}: \mathrm{Pd}$ mol ratio $=5: 1,6 \mathrm{~mL}$ of a $32 \mathrm{wt} \%$ solution of BAIL in methanol, $\mathrm{P}\left(\mathrm{CO}: \mathrm{C}_{2} \mathrm{H}_{4}: \mathrm{Ar}=2: 2: 1\right)=22$ bars, $T=$ $80{ }^{\circ} \mathrm{C}, t=20 \mathrm{~min}$ ). After reaction cycle 5,10 and 15 the MP were decanted and excess of the organic phase was evaporated and the IL phase containing the catalyst was recovered.

metal precipitation ${ }^{17}$ - in the presence of the BAIL could enable Pd reduction or destabilization and further decomposition yielding Pd-black during the in situ complex formation. Notably, the reaction solution phase-separated after the fifth run (when a considerable amount of MP was formed) into an upper phase containing the MP and a lower phase containing the catalyst system dissolved in the BAIL, thus confirming the basis of the process concept to work.

Instead of performing the complex formation in situ in the presence of the reactants, pre-formation of the catalytic system by stirring the BAIL, $\mathrm{Pd}(\mathrm{OAc})_{2}$ and DTBPMB ligand in $\mathrm{MeOH}$ under Ar for $2 \mathrm{~h}$ at $80^{\circ} \mathrm{C}$ proved highly useful to avoid the formation of Pd-black and thus improve the reusability of the catalyst system. Hence, when the catalytic system was preformed it maintained its excellent performance of $>97 \% \mathrm{MP}$ yield during fifteen recycle experiments (Fig. 6), and after every fifth reaction the BAIL-catalyst system was recovered without the observation of any appreciable Pd-black (Fig. 5b-f) - or at least significantly less compared to the analogous reaction with the in situ formed catalyst system (Fig. 5a). This confirms that pre-formation of the catalytic system before mixing with the substrates ( $\mathrm{CO}$ and ethylene) is essential to confer stability under the examined reaction conditions.

\section{Conclusions}

Efficient and durable Pd-diphosphine catalyst systems were prepared with BAILs and successfully applied in selective methoxycarbonylation of ethylene to obtain MP. Excellent results in terms of conversion and selectivity ( $>99 \%$ MP yield) were achieved. The application of BAILs allowed re-using the catalytic systems for fifteen times without any loss of performance, thus corroborating an efficient immobilization of the palladium complex catalyst. In addition, the use of BAILs provided a biphasic system with the MP product affording easy product separation and catalyst recovery - two features which are imperative for possible future industrial exploration.

\section{Acknowledgements}

The Danish Council for Independent Research - Technology and Production Sciences (project no. 11-106979) has provided support for this work.

\section{References}

1 (a) B. Beller and A. M. Tafesh, in Applied Homogeneous Catalysis with Organometallic Compounds, ed. W. A. Hermann, Wiley-VCH, Weinheim, 1996; (b) P. W. N. M. van Leeuwen, in Homogeneous Catalysis, Understanding the Art, ed. Kluwer Academic Publishers, Dordrecht, The Netherlands, 2004; (c) Catalytic Carbonylation Reactions, Topics in Organometallic Chemistry, ed. M. Beller, Springer, Berlin, 2006.

2 (a) E. Drent and P. H. M. Budzelaar, Chem. Rev., 1996, 96, 663; (b) R. A. M. Robertson and D. J. Cole-Hamilton, Coord. Chem. Rev., 2002, 225, 67; (c) G. R. Eastham, R. P. Tooze, M. Kilner, D. F. Foster and D. J. Cole-Hamilton, J. Chem. Soc., Dalton Trans., 2002, 8, 1613; (d) A. Vavasori, G. Cavinato and L. Toniolo, J. Organomet. Chem., 2000, 601, 100; (e) C. Bianchini, A. Meli, W. Oberhauser, S. Parisel, O. V. Gusev, A. M. Kalsin, N. V. Vologdin and F. M. Dolgushin, J. Mol. Catal. A: Chem., 2004, 224, 35; (f) C. Godard, B. K. Muñoz, A. Ruiz and C. Claver, Dalton Trans., 2008, 853.

3 A. Brennführer, H. Neumann and M. Beller, ChemCatChem, 2009, 1, 28.

4 (a) A. H. Tullo, Chem. Eng. News, 2009, 87(42), 22; (b) B. Harris, Ingenia, 2010, 45, 18.

5 (a) W. Clegg, G. R. Eastham, M. R. J. Elsegood, R. P. Tooze, X. L. Wang and K. Whiston, Chem. Commun., 1999, 1877; (b) J. M. D. Jeroen, D. Berth-Jan, J. E. Cornelis and K. V. Gerard, Adv. Synth. Catal., 2006, 348, 1447; (c) W. G. Reman, G. B. J. De Boer, S. A. J. Van Langen and A. Nahuijsen, Eur. Pat., EP 411721 A3, 1989 (to Shell).

6 (a) C. J. Rodriguez, D. F. Foster, G. R. Eastham and D. J. Cole-Hamilton, Chem. Commun., 2004, 1720; (b) G. P. C. M. Dekker, C. J. Elsevier, K. Vrieze, P. W. N. M. van Leeuwen and C. F. Roobeek, J. Organomet. Chem., 1992, 430, 357; (c) B. A. Markies, D. Kruis, M. H. P. Rietveld, K. A. N. Verkerk, J. Boersma, H. Kooijman, M. Lakin, A. L. Spek and G. van Koten, J. Am. Chem. Soc., 1995, 117, 5263.

7 (a) C. Bianchini and A. Meli, Coord. Chem. Rev., 2002, 225, 35; (b) M. A. Zuideveld, P. C. J. Kramer, P. W. N. M. van Leeuwen, P. A. A. Klusener, H. A. Stil and C. F. Roobek, J. Am. Chem. Soc., 1998, 120, 7977; (c) E. Drent, P. Arnoldy and P. H. M. Budzelaar, J. Organomet. Chem., 1994, 475, 57; 
(d) R. A. M. Robertson, A. D. Poole, M. J. Payne and D. J. Cole-Hamilton, Chem. Commun., 2001, 47.

8 (a) H. Ooka, T. Inoue, S. Itsuno and M. Tanaka, Chem. Commun., 2005, 1173; (b) A. C. Ferreira, R. Crous, L. Bennie, A. M. M. Meij, K. Blann, B. C. B. Bezuidenhoudt, D. A. Young, M. J. Green and A. Roodt, Angew. Chem., Int. Ed., 2007, 46, 2273; (c) T. O. Vieira, M. J. Green and H. Alper, Org. Lett., 2006, 8, 6143; (d) D. Bradley, G. Williams, M. L. Shaw, M. J. Green and C. W. Holzapfel, Angew. Chem., Int. Ed., 2008, 120, 570.

9 M. Haumann and A. Riisager, Chem. Rev., 2008, 108, 1474.

10 Ionic Liquids in Synthesis, ed. P. Wasserscheid and T. Welton, Wiley, 2007.

11 (a) F. Dong, C. Jian, F. Zhenghao, G. Kai and L. Zuliang, Catal. Commun., 2008, 9, 1924; (b) X. Lia, W. Eli and G. Lia, Catal. Commun., 2008, 9, 2264; (c) P. Wasserscheid, M. Sesing and W. Korth, Green Chem., 2002, 4, 134; (d) D. Li, F. Shi, S. Guo and Y. Deng, Tetrahedron Lett., 2004, 45, 265; (e) Y. L. Gu, J. Mol. Catal. A: Chem., 2004, 71, 212; $(f)$ S. Saravanamurugan and A. Riisager, Catal. Today, 2013, 200, 94; (g) J. C. Serrrano-Ruiz, J. M. Campelo, M. Francavilla, A. A. Romero, R. Luque, C. Menendez-
Vazquez, A. B. Garcia and E. J. Garcia-Suarez, Catal. Sci. Tech., 2012, 9, 1828; (h) H. Zhang, F. Xu, G. Zhang and C. Wang, Green Chem., 2007, 9, 1208.

12 A. C. Cole, J. L. Jensen, I. Ntai, K. L. T. Tran, K. J. Weaver, D. C. Forbes and J. H. Davis, J. Am. Chem. Soc., 2002, 124, 5962.

13 S. G. Khokarade, E. J. García-Suárez, J. Xiong, U. V. Mentzel, R. Fehrmann and A. Riisager, Catal. Commun., 2013, DOI: 10.1016/j.catcom.2013.09.005.

14 (a) C. Thomazeau, H. Olivier-Bourbigou, L. Magna, S. Luts and B. Gilbert, J. Am. Chem. Soc., 2003, 125, 5264; (b) Z. Y. Du, Z. P. Li, S. Guo, J. Zhang and Y. Q. Deng, J. Phys. Chem. B, 2005, 109, 19542.

15 J. Luo, O. Conrad and I. F. J. Vankelecom, J. Mater. Chem., 2012, 22, 20574.

16 D. J. Cole-Hamilton and R. P. Tooze, Catalyst Separation, Recovery and Recycling, Springer, Netherlands, 2006.

17 (a) G. R. Eastham, Studies on the palladium catalysed methoxycarbonylation of ethane, Durham theses, Durham University, 1998; (b) C. Bianchini and A. Meli, Coord. Chem. Rev., 2002, 225, 35; (c) P. W. N. M. van Leeuwen, Appl. Catal., A, 2001, 212, 61. 